\title{
Molecular breeding of a novel orange- brown tomato fruit with enhanced beta-carotene and chlorophyll accumulation
}

\author{
Ranjith Kumar Manoharan ${ }^{1+}$, Hee-Jeong Jung ${ }^{1+}$, Indeok Hwang ${ }^{1}$, Namhee Jeong ${ }^{1}$, Kang Hee Kho ${ }^{2}$, \\ Mi-Young Chung ${ }^{3}$ and III-Sup Nou ${ }^{1,4^{*}}$
}

\begin{abstract}
Background: Tomatoes provide a significant dietary source of the carotenoids, lycopene and $\beta$-carotene. During ripening, carotenoid accumulation determines the fruit colors while chlorophyll degradation. These traits have been, and continue to be, a significant focus for plant breeding efforts. Previous work has found strong evidence for a relationship between $C Y C-B$ gene expression and the orange color of fleshy fruit. Other work has identified a point mutation in SGR that impedes chlorophyll degradation and causes brown flesh color to be retained in some tomato varieties.

Methods: We crossed two inbred lines, KNY2 (orange) and KNB1 (brown) and evaluated the relationship between these genes for their effect on fruit color. Phenotypes of F2 generation plants were analyzed and a novel 'orange-brown' fruit color was identified.

Results: We confirm two SNPS, one in CYC-B and another in SGR gene sequence, associated with segregation of 'orange-brown' fruit color in F2 generation. The carotenoid and chlorophyll content of a fleshy fruit was assessed across the different phenotypes and showed a strong correlation with expression pattern of carotenoid biosynthesis genes and SGR function. The orange-brown fruit has high $\beta$-carotene and chlorophyll. Our results provide valuable information for breeders to develop tomato fruit of a novel color using molecular markers.
\end{abstract}

Keywords: Orange-brown tomato, CYC-B, $\beta$-carotene, SGR, Chlorophyll

\section{Background}

Tomatoes are predominantly grown as an agricultural crop and are considered a healthy food due to their high nutritional value [1]. Tomatoes are cholesterol free, rich in fiber and protein, and low in fat and calories. Approximately $80 \%$ of the tomatoes produced are used in tomatobased foods that include tomato juice, puree, paste, sauce and salsa [2]. Daily consumption of tomato sauce has been shown to reduce DNA damage in white blood cells and cancerous prostate tissues [3]. In addition, consumption

\footnotetext{
* Correspondence: nis@sunchon.ac.kr

${ }^{\dagger}$ Equal contributors

'Department of Horticulture, Sunchon National University, 255, Jungang-ro, Suncheon, Jeonnam 57922, Republic of Korea

${ }^{4}$ Present address: Department of Horticulture, Sunchon National University, 255 Jungang-ro, Suncheon, Jeonnam 57922, Republic of Korea

Full list of author information is available at the end of the article
}

of lycopene-containing foods can reduce the risk of cardiovascular disease and breast cancer [4]. Therefore, many attempts have been made to develop high-lycopene tomatoes using conventional breeding techniques and genetic manipulation. In addition to lycopene content, new color developments also attract consumers in the fresh market. Tomato fruit color is an important indicator of eating quality for consumers and thus considerable research has been directed towards its characterization and measurement [5]. During the ripening stage, tomato color brightens due to carotenoid, lycopene accumulation, independently or in concert with chlorophyll degradation [6]. Subsequent lycopene accumulation during the final stages of fruit ripening affects color development and the health benefits, both important traits for consumers. In green vegetables and leaves, lycopene is concealed by green 
chlorophyllic pigments. However, in most fruits, lycopene and other carotenoids are responsible for the bright color development during the ripening stage [7]. Lycopene accounts for more than $80 \%$ of the accumulated carotenes in ripe tomato fruits. While $\beta$-carotene accumulates to a lesser degree, it also constitutes a sizable portion of total carotene accumulation. Both lycopene and $\beta$-carotene are essential to fulfill the nutritional requirements of a healthy animal and human diet [8].

Carotenoid biosynthesis in plants occurs preferentially via the 1-deoxy-D-xylulose-5-phosphate (DOXP) pathway rather than the previously assumed mevalonic acid pathway $[9,10]$. Although both pathways produce isopentenyl pyrophosphate (IPP), the DOXP pathway [11] also leads to the formation of the plastidic carotenoids phytol, plastoquinone-9, and diterpenes (Fig. 1). IPP is a precursor of geranylgeranyl pyrophosphate (GGPP), which is a

1-deoxy-D-xylulose-5-phosphate (DOXP)

DXR, HDR, DXS

Isopentenyl diphosphate (IPP)

GGPPS

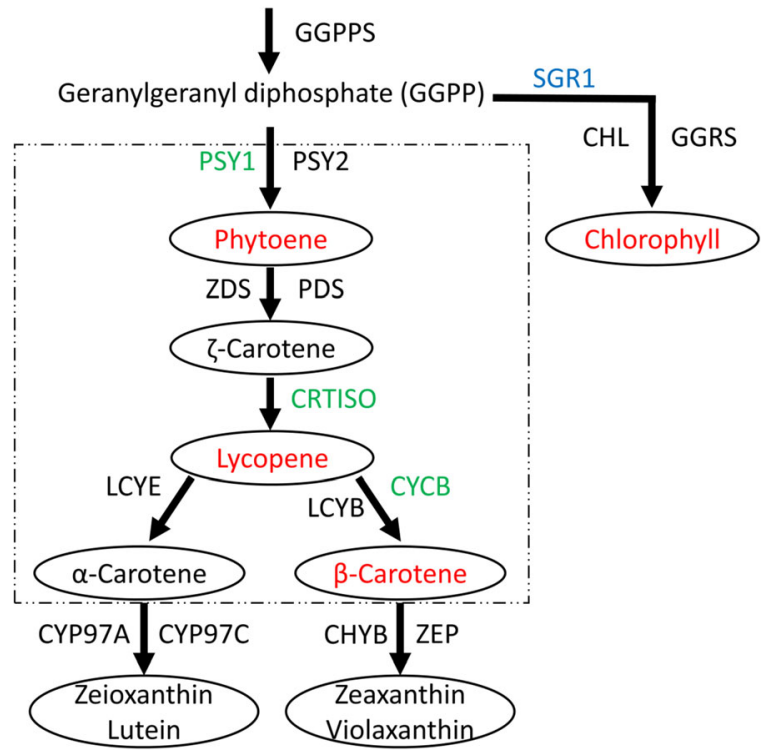

Fig. 1 Metabolic pathways involved in biosynthesis of carotenoids via DOXP route with related genes of tomato. The enzymes involved in the carotenoid synthesis are: DOXP reductoisomerase (DXR), hydroxymethylbutenyl diphosphate synthase (HDS), hydroxymethylbutenyl diphosphate reductase (HDR), geranylgeranyl pyrophosphate synthase (GGPPS), phytoene synthase (PSY), phytoene desaturase (PDS), z-carotene desaturase (ZDS), carotene isomerase (CRTISO), lycopene $\varepsilon$ cyclase (LCYE), lycopene $\beta$ cyclase (LCYB), $\beta$-carotene hydroxylase (CHYB), cytochrome P450-type monooxygenase 97C (CYP97C), zeaxanthin epoxidase (ZEP), geranylgeranyl oxidase (GGRS), chlorophyll synthase (CHL). The carotenoids measured by HPLC are denoted in red color. Dotted rectangle denote carotenoid pathway, genes analyzed in this work are colored in green and regulatory gene SGR is colored in blue carotenoid precursor. Using phytoene synthase (PSY) as a catalyst with GGPP leads to production of phytoene [12, 13]. The phytoene desaturase gene (PDS) converts phytoene to $\zeta$-carotene. Three isoforms of the PSY gene have been identified in tomato. The PSY1 isoform is responsible for fruit ripening, whereas PSY2 and PSY3 are likely predominant in green tissues and roots, respectively [14-16]. PSY1 and PDS genes are upregulated during fruit ripening, while genes for enzymes carrying out cyclisation of lycopene such as $\beta$-Lcy and $\varepsilon$-Lcy are downregulated, resulting in low levels of $\beta$-carotene during tomato ripening [17]. Our previous report had showed the evidence of $C Y C-B$ ( $\beta$-lycopene cyclase) gene expression associated with orange color of fleshy fruit in tomato [16].

Another important gene, SGR (STAY-GREEN) associated with color has been identified previously in some plant species [18-20]. SGR mutants showed brown color due to carotenoid accumulation and fail to degrade chlorophyll completely at ripening stage $[21,22]$. For instance, SGR mutants that have been identified in other plant species (Arabidopsis, pepper, pea, and meadow fescue) displayed green phenotypes due to inhibition of chlorophyll degradation [19, 23-27]. Barry and Pandey [30] had reported that point mutation in $S G R$ gene causes loss of protein function and leads to inhibit chlorophyll degradation which exhibited green fleshy fruit color in 'Black cherry' variety. Flavonoids also play an important role in determining tomato fruit color. Flavonoids primarily accumulate in the tomato fruit peel, and are absent in the flesh, due to a lack of expression of flavonoid biosynthesis genes in flesh tissues [28, 29].

Because of their importance, our study focused on developing a new tomato fruit color that is enriched for $\beta$-carotene and chlorophyll content. Thus, our work evaluated the segregation of fruit color and, $\beta$-carotene and chlorophyll level, in the F1 and F2 populations, developed by crossing orange and brown fruit.

\section{Methods \\ Plant material}

Tomato seeds of inbred lines KNY2 (orange) and KNB1 (brown) were obtained from Kana Seed Co. Ltd (Korea). Seeds were sown on moist filter paper in petri dishes and germinated at $30{ }^{\circ} \mathrm{C}$ in the dark. The germinated seeds were transferred to plastic trays containing soil mix and maintained at growth room conditions. When plants (F1 and F2) had four true leaves, they were transplanted into plastic pots and grown in greenhouse $\left(25{ }^{\circ} \mathrm{C}\right.$ day/18 ${ }^{\circ} \mathrm{C}$ night, $70 \%$ air humidity and natural light) at Sunchon National University, Korea. Furthermore, three fruits were harvested from individual plant at ripe (57 days after pollination (DAP)) stage for HPLC analysis. Fruit color was confirmed from 6 F1 plants, 192 F2 plants (obtained from 6 F1 plants) and described in results section. 


\section{RNA extraction and PCR amplification}

Total RNA was extracted from fleshy fruit tissue at early (E, 17 DAP), mature (M, 39 DAP), turning ( $\mathrm{T}, 45 \mathrm{DAP})$, and ripe (R, 57 DAP) stages using an RNA extraction kit (Qiagen, USA) according to manufacturer's instructions. High-quality RNA was eluted in RNase-free water and treated with RNase-free DNase I (Qiagen) before cDNA synthesis. Quantitative RT-PCR (RT-qPCR) was conducted using cDNA synthesized from the RNA of each stage. PCR was performed with the following conditions: initial denaturation at $95{ }^{\circ} \mathrm{C}$ for $10 \mathrm{~min}$, followed by 40 cycles of $95^{\circ} \mathrm{C}$ for $20 \mathrm{~s}, 60^{\circ} \mathrm{C}$ for $20 \mathrm{~s}, 72{ }^{\circ} \mathrm{C}$ for $40 \mathrm{~s}$ and final extension at $72{ }^{\circ} \mathrm{C}$ for $2 \mathrm{~min}$.

\section{SNP detection}

Single nucleotide polymorphisms (SNPs) were detected using 3'-blocked and unlabeled oligonucleotide probes (HybProbe). PCR was performed using LightCycler 480 Resolight saturating dye (Roche, Germany) to generate melting curves characteristic of the genotype under the probe. Melting curves were generated and analyzed using the LightCycler 96 Instrument System (Roche, Germany). PCR reactions were performed with a $95{ }^{\circ} \mathrm{C}$ pre-denaturation for $5 \mathrm{~min}$, followed by 45 cycles of denaturation at $95{ }^{\circ} \mathrm{C}$ for $20 \mathrm{~s}$, annealing at $60{ }^{\circ} \mathrm{C}$ for $20 \mathrm{~s}$, and extension at $72{ }^{\circ} \mathrm{C}$ for $30 \mathrm{~s}$, with a final extension s at $72{ }^{\circ} \mathrm{C}$ for $40 \mathrm{~s}$. Primer and probe sets used for SNP detection are described in Additional file 2 Table S1.

\section{HPLC analysis}

Standards for $\beta$-carotene, lycopene, phytoene, and chlorophyll were purchased from Sigma- Aldrich (Sigma Co., USA). The carotenoids and chlorophyll were separated using reverse phase columns (Kinetex $206 \mu \mathrm{m}, \mathrm{C} 18$ 100A, $100 \times$ $4.60 \mathrm{~mm}$, Phenomenex, USA). The whole fruit extracts were filtered with a $0.2 \mu \mathrm{m}$ PTFE filter prior to injection. Mobile phase A was 78\% methanol and B was 100\% ethyl acetate. Release conditions were 0-5 min, 0\% B; 5-15 min, 10\% B; $15-20 \mathrm{~min}, 100 \% \mathrm{~B} ; 20-30 \mathrm{~min}, 0 \% \mathrm{~B}$ at a flow rate of $1 \mathrm{~mL} /$ min. The phytoene, carotenoids and chlorophyll were identified and quantified based on the retention time and the absorbance between $280 \mathrm{~nm}, 450 \mathrm{~nm}$ and $660 \mathrm{~nm}$ of standards. The values represent the mean of three biological replicates.

\section{Statistical analysis}

The EF1 $\alpha$ gene was used as reference for normalization. The relative gene expression was calculated based on $\Delta \Delta \mathrm{Ct}$ method (LightCycler ${ }^{\circ} 96$, Roche Diagnostics, Mannheim, Germany). Data are presented as the mean of three biological replicates. The data were analyzed using a Tukey Pairwise Comparisons test $(P<0.05)$ in the Minitab 17 Statistical Software (State College, Pennsylvania, USA). Chi-square analysis to test goodness-of-fit was performed using Graphpad Prism 7.02 (Graphpad software, California, USA).

\section{Results and discussion \\ Segregation analysis}

Inbred lines KNY2 and KNB1 were characterized for their fruit phenotype during ripening (Additional file 1: Fig. S1) and crossed. Fruit color phenotypes of F1 and F2 progeny were analyzed. All F1 progeny produced orange-colored fruit suggesting that orange color is dominantly inherited over other fruit colors in this experiment [16] (Additional file 1: Fig. S2). To examine the genotypic variation in the F2 generations, SNP sites of SGR and CYC-B genes were identified $[16,30]$. The $S G R$ gene plays an important role in the regulation of chlorophyll degradation in tomato fruits and leaves [31,32]. The lack of SGR protein function in KNB1 is likely due to a $\mathrm{C} \rightarrow \mathrm{T}$ point mutation at position $371 \mathrm{bp}$ from the start codon (ATG) in the SGR genomic sequence [30]. This modification results in brown-colored fruit, suggesting that chlorophyll is retained and conceals the pigmentation in the fruit (Fig. 2a, c). This observation confirms previous work by Barry and Pandey [30] identified this allele as responsible for the brown fruit color phenotype. Another gene that plays an important role in orange color formation and involved in improving carotenoid content in tomato fruit is $C Y C-B[33,34]$. This gene is suggested to play a major role in fruit pigmentation of the KNY2 inbred during the ripening stages. In a previous study, we detected and confirmed a SNP at the -77 position of the $C Y C-B$ gene that showed perfect association and a dominant phenotype in KNY2 for orange fruit color [16] (Fig. 2b, d). In the F1 generation, the 371 SNP site of SGR was detected as CT heterozygous which ' $\mathrm{T}$ ' is a recessive allele (Fig. 2c). Similarly, the -77 SNP position of $C Y C-B$ was detected as GT heterozygous (Fig. 2d). These results suggest that a ' $\mathrm{T}$ ' represents a dominant allele in $C Y C-B$ genes and leads to orange color formation in the $\mathrm{F} 1$ generation.

Fruit color phenotypes were scored in the F2 generation and the segregation ratios were analyzed with the corresponding genotypes. Four color phenotypes were observed in the F2 generation, namely red, orange, brown and orange-brown in the ripe stage ( $\mathrm{R}, 57 \mathrm{DAP}$ ) (Fig. 3). Genotypes TT, CT and CC were identified at the 371 (SGR) SNP position whereas TT, GT and GG genotypes were identified at the $-77(C Y C-B)$ SNP position (Table 1). In total, $192 \mathrm{~F} 2$ plants were evaluated (Table 1). Interestingly, a new 'orange-brown' color was identified in this F2 population and was found to segregate approximating a 9:3:3:1 (Orange: Red: Orange-brown: Brown) ratio (Table 2). The chi-square for F2 progeny segregation ratio showed an acceptable fit to 9:3:3:1 (Chi-square $\left(X^{2}\right)=0.370, P>0.90$ ). The genotype at the SGR 371 SNP site was confirmed to show approximating a 1:2:1 ratio of TT: CT: CC in the F2 plants. The F2 plants with a TT genotype were either orange-brown or brown in color, whereas the F2 plants with a genotype of $\mathrm{CT}$ and $\mathrm{CC}$ were either red or orange (Table 1). The CYC$B-77$ SNP site with a TT or GT genotype corresponded 

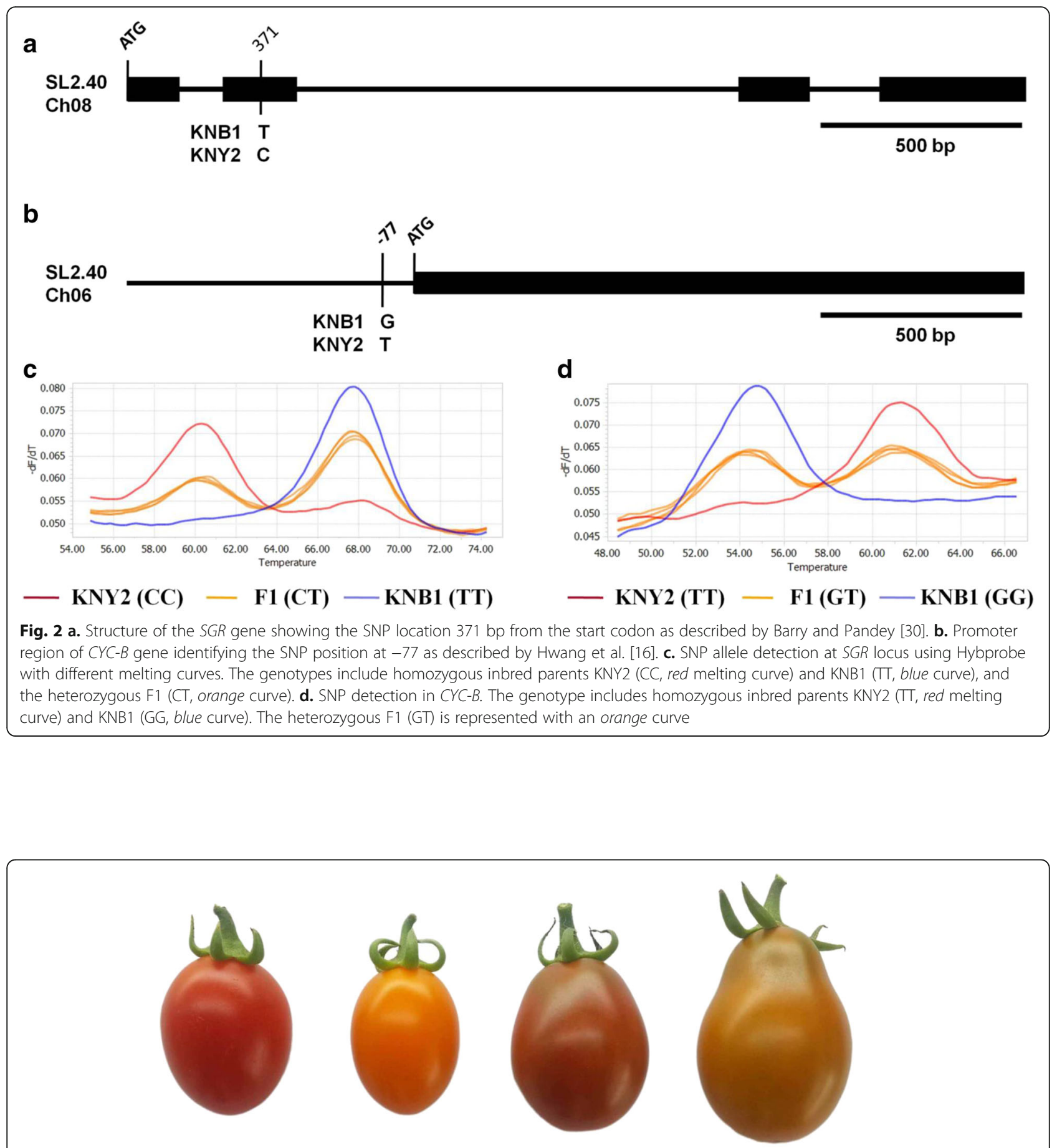

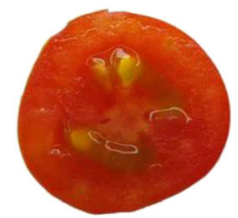

Red

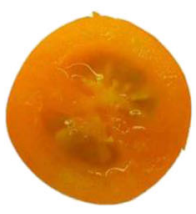

Orange

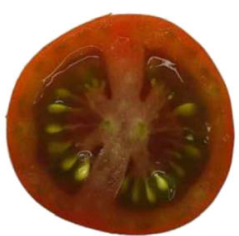

Brown

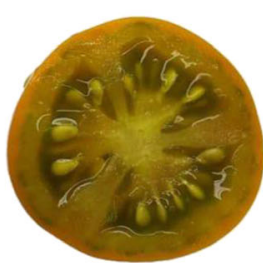

Orange brown

Fig. 3 The fruit colors observed in the F2 generation at ripe stage (R, 57 DAP) 
Table 1 Phenotypic and genotypic segregation of F2 generation plants from KNB1 x KNY2

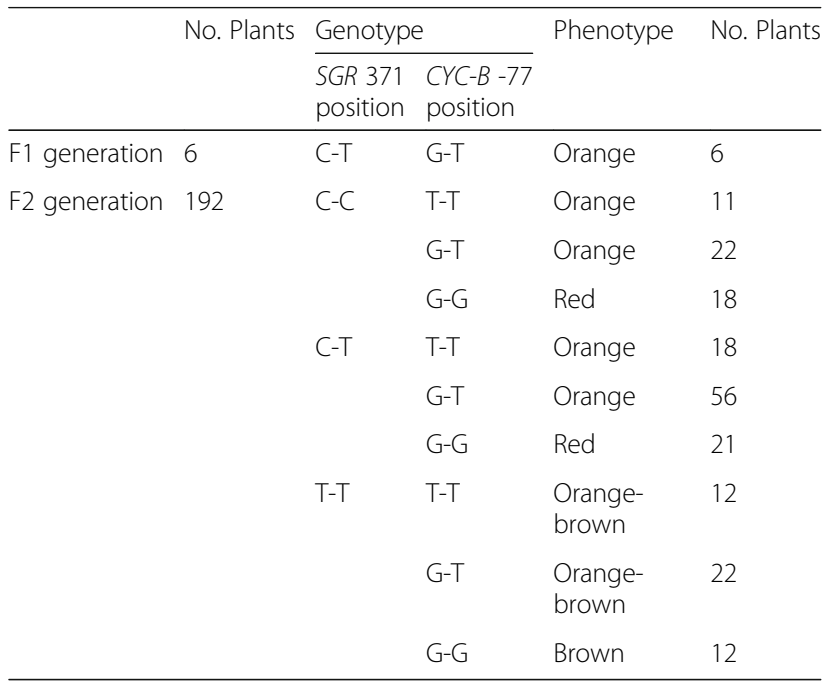

with an orange or orange-brown phenotype while GG genotypes were either red or brown (Table 1). Fruit color was dependent on the genotypes at both the $S G R$ and $C Y C-B$.

\section{Expression of $C Y C-B$ and $S G R$}

The aim of this work was to identify the relationship between fruit color phenotype and variant genotypes in a segregating F2 population. Our previous work reported that the transcript level of $C Y C-B$ regulates orange color in tomato fruit [16]. Researchers focused on carotenoid content [17, 35] were also reported that regulation of $C Y C-B$ increases the accumulation of $\beta$-carotene in the tomato fruit during ripening. Similar results were observed during fruit development in bell pepper, a related species [36-39]. Based on the previous findings, we compared transcript levels of $C Y C-B$ among the different phenotypes observed in this experiment. The mRNA levels of $C Y C-B$ were analyzed during ripening at early, mature, turning and ripe stages as described by [40]. Interestingly, the orange-brown phenotype showed increased expression of $C Y C-B$ during fruit development, similar to that observed in the orange phenotype (Fig. 4). The level of $C Y C-B$ expression was significantly (Tukey Pairwise Comparisons test, $\mathrm{p}<0.05$ ) higher at the turning stage of ripening than in earlier stages in both phenotypes (Fig. 4). This corroborates our hypothesis that expression of $C Y C-B$ contributes to orange coloration as well as to the orange-brown color. As expected, the transcript level of $C Y C-B$ was not increased in red or brown phenotypes during ripening. The dramatic increase in expression of $C Y C-B$ during $\mathrm{T}$ and $\mathrm{R}$ stages of orange and orange-brown phenotypes suggests high $\beta$ carotene levels in both phenotypes. In addition to $C Y C$ $B$, the expression of biosynthetic genes such as PSY1, carotenoid isomerase (CRTISO) and SGR was examined (Additional file 1: Fig. S3). The mRNA levels of these three genes showed a pattern of increased expression during ripening across all four phenotypes. No significant difference (Tukey Pairwise Comparisons test, $p<0.05$ ) in gene expression was observed among the phenotypes during ripening (Additional file 1: Fig. S3).

Barry and Pandey [30] reported that a SNP $(\mathrm{C} \rightarrow \mathrm{T})$ at nucleotide 371 in the tomato $S G R$ gene results in a mutation that truncates the protein at glutamine 91. Characterized in the variety 'Black Cherry', the truncation introduces a premature stop codon and is predicated to carry null alleles that cause complete loss of protein function. Varieties with this SNP could thus inhibit chlorophyll degradation and retain green flesh. Consistent with these results, the new orange-brown phenotype reported herein retains brown coloration may be due to loss of SGR protein function while concurrent high expression levels of $C Y C-B$ result in orange fruit color. This combination could explain the orange-brown phenotype we observed.

\section{HPLC analysis of carotenoid and chlorophyll content}

We investigated the carotenoid and chlorophyll content of tomato fruit during various developmental stages of ripening. All phenotypes identified in the F2 population, red, orange, brown and orange-brown, were analyzed in $\mathrm{M}, \mathrm{T}$ and $\mathrm{R}$ stages of ripening. Lycopene, $\beta$-carotene and phytoene levels were shown to increase as the fruit progressed through ripening stages for all four phenotypes (Table 3). The orange-brown phenotype was observed to have low levels of lycopene and high levels of $\beta$ carotene, similar to the orange phenotype in $\mathrm{R}$ stage (Table 3). This result was consistent with our transcript analysis showing that higher expression of $C Y C-B$ correlates with accumulation of $\beta$-carotene and causes orange color pigmentation [17] (Fig. 4). The high chlorophyll content after ripening of the orange-brown phenotype was similar in level to the brown phenotype (Table 3). By contrast, chlorophyll content was decreased in red

Table 2 Segregation ratio of fruit color in F2 generation plants from KNB1 x KNY2

\begin{tabular}{lllllllll}
\hline Cross & \multicolumn{2}{l}{$\mathrm{F}_{2}$ Segregation } & & & & \multirow{2}{*}{ X2 (9:3:3:1) } & P-value \\
\cline { 2 - 7 } & & Orange & Red & Orange-brown & Brown & Total & & \\
\hline No. Plants & Observed & 107 & 39 & 34 & 12 & 192 & 0.370 & $0.95-0.90$ \\
& Expected & 108 & 36 & 36 & 12 & 192 & \\
\hline
\end{tabular}



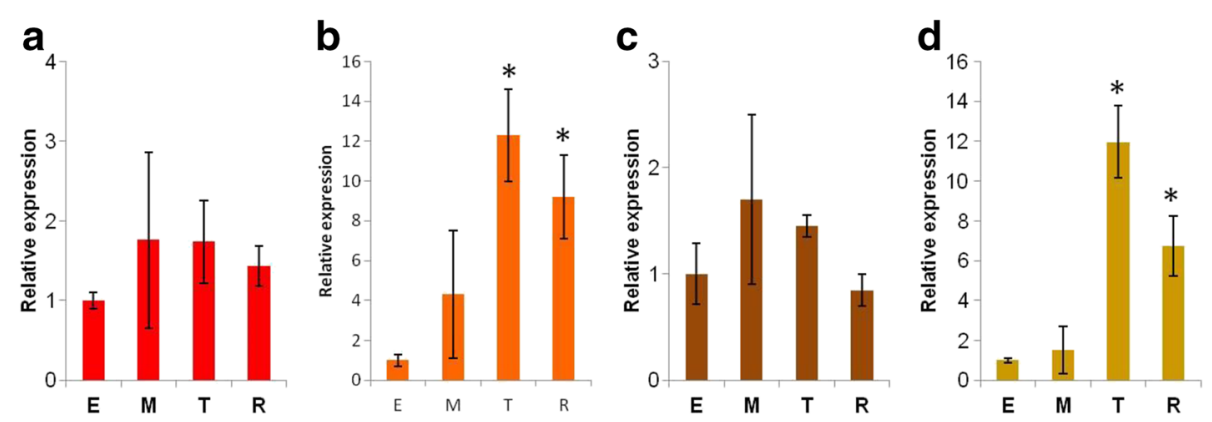

Fig. 4 Expression of the CYC-B gene during fruit development in F2 generation plants. RNA was extracted from fruit samples at early (E), mature $(\mathrm{M})$, turning $(T)$, and ripe (R) developmental stages. Relative amounts of mRNA were determined by RT-qPCR after normalizing with EF1a transcript. The relative expression levels of CYC-B were compared to early stage (E) level (set to 1) in each F2 plant. Data represent an average \pm s.e.m of three biological replicates and asterisk indicates values significantly different $(p<0.05)$. a: Red, b: Orange, c: Brown, d: Orange-brown

and orange phenotypes at ripening, while there was no significant difference between brown and orange-brown phenotypes $(p<0.05)$. Carotenoid and chlorophyll of brown tomato phenotypes (SGR) have positive effect on human health [41, 42]. Chlorophyll in tomato fruits combined with lycopene increased antioxidant activity [43] and protect cells against oxidants and electrophiles [44]. Chlorophyll in SGR mutant tomato fruits could reduce risk of colon cancer in humans [45] and their derivatives can be used as agents of photodynamic therapy in cancer [46]. SGR mutant varieties also have agronomical advantages, positive yield is recorded in maize $S G R$ variety FS854 and SGR rice variety SNU-SG1 [47]. In addition, increased water, carbohydrates, and protein content in husks, cobs, and seeds are reported in SGR maize variety L087602. SGR mutant lines of wheat showed heat tolerance at terminal growth stage [48]. Therefore, it assumes, SGR mutant cultivars could be good source of better yield, fruit quality, and heat stress tolerance in tomato breeding. We found that retention of chlorophyll together with higher $\beta$-carotene produced 'orange-brown' phenotype of tomato.

\section{Conclusion}

The present study developed a new tomato fruit color with an orange-brown phenotype. This fruit has high $\beta$ carotene content and retains chlorophyll through ripening. The expression of $C Y C-B$ mRNA coincided with the accumulation of $\beta$-carotene. The point mutation in $S G R$ gene causes loss of protein function and leads to inhibit chlorophyll degradation. Present work provides insight into development of genotypes with enhanced $\beta$-carotene accumulation and chlorophyll retention in tomato fruits. Combination of these two SNPs would be suitable for breeding 'orange-brown' color tomato cultivars.

Table 3 Phytoene, lycopene, $\beta$-carotene, and chlorophyll content in F2 generation plants. The carotenoid pigments were quantified using HPLC ( $\mu \mathrm{g} / \mathrm{g}$ fresh weight) $(n=3, \pm$ s.e.m) during mature $(M)$, turning $(T)$, and ripe $(\mathrm{R})$ stages of ripening

\begin{tabular}{|c|c|c|c|c|c|}
\hline Selected plant in F2 generation & Stage & Phytoene & Lycopene & $\beta$-carotene & Chlorophyll $(a+b)$ \\
\hline \multirow[t]{3}{*}{$\overline{\text { Red }}$} & M & $0.01 \pm 0.14$ & $0.04 \pm 0.12$ & $0.91 \pm 0.61$ & $2.84 \pm 0.17$ \\
\hline & T & $0.46 \pm 0.42$ & $14.03 \pm 0.02$ & $2.97 \pm 0.35$ & $0.14 \pm 0.38$ \\
\hline & $\mathrm{R}$ & $1.68 \pm 0.21$ & $32.12 \pm 0.64$ & $4.03 \pm 0.64$ & $0.08 \pm 0.12$ \\
\hline \multirow[t]{3}{*}{ Orange } & M & $0.01 \pm 0.34$ & $0.02 \pm 0.07$ & $1.16 \pm 0.28$ & $2.54 \pm 0.16$ \\
\hline & $\mathrm{T}$ & $0.18 \pm 0.13$ & $0.16 \pm 0.27$ & $7.94 \pm 2.32^{*}$ & $0.22 \pm 0.03$ \\
\hline & $\mathrm{R}$ & $0.21 \pm 0.15$ & $0.58 \pm 0.45$ & $11.07 \pm 1.61^{*}$ & $0.07 \pm 0.07$ \\
\hline \multirow[t]{3}{*}{ Brown } & M & $0.01 \pm 0.03$ & $0.01 \pm 0.03$ & $1.12 \pm 0.26$ & $5.84 \pm 0.12$ \\
\hline & $\mathrm{T}$ & $0.24 \pm 0.02$ & $8.27 \pm 0.28$ & $1.84 \pm 0.17$ & $2.97 \pm 1.06^{*}$ \\
\hline & $\mathrm{R}$ & $0.56 \pm 0.14$ & $27.64 \pm 0.17$ & $2.62 \pm 0.13$ & $2.05 \pm 0.57^{*}$ \\
\hline \multirow[t]{3}{*}{ Orange-brown } & M & $0.01 \pm 0.07$ & $0.13 \pm 0.16$ & $1.03 \pm 0.57$ & $3.27 \pm 0.16$ \\
\hline & $\mathrm{T}$ & $0.12 \pm 0.17$ & $0.34 \pm 0.28$ & $10.97 \pm 1.38^{*}$ & $2.68 \pm 0.26^{*}$ \\
\hline & R & $0.18 \pm 0.03$ & $0.46 \pm 0.31$ & $11.74 \pm 2.28^{*}$ & $2.03 \pm 0.68^{*}$ \\
\hline
\end{tabular}




\section{Additional files}

Additional file 1: Fig. S1. Phenotype of KNB1 and KNY2 tomato fruits at various fruit ripening stages. $E$, early stage; $M$, mature stage; $T$, turning stage; $R$, ripe stage. Fig. S2. Fruit color observed in the $F 1$ generation of a cross between KNB1 and KNY2. Fig. S3. Relative expression of PSY1 (A, $D, G, J), C R T I S O(B, E, H, K)$ and $S G R(C, F, I, L)$ during fruit development of various inbred lines. Relative amounts of mRNA were determined by RTqPCR after normalizing with EFla transcript. Relative expression levels were compared to early stage (E) level (set to 1 ) in each F2 plant. Data represent an average \pm s.e.m of three biological replicates and asterisk indicates values significantly different $(p<0.05)$. A-C: red fruit, D-F: orange fruit, G-I: brown fruit, J-L: orange-brown fruit. E, early stage; $M$, mature stage; $T$, turning stage; $R$, ripe stage. (PPTX $413 \mathrm{~kb}$ )

Additional file 2: Table S1 Primers and probes used in this study. (DOCX $14 \mathrm{~kb}$ )

\section{Acknowledgements}

This research was supported by the Golden Seed Project (Center for Horticultural Seed Development), Ministry of Agriculture, Food and Rural Affairs (MAFRA), Ministry of Oceans and Fisheries (MOF), Rural Development Administration (RDA) and Korea Forest Service (KFS).

\section{Availability of data and materials}

Plant materials and cDNA samples are available from the authors.

\section{Authors' contributions}

ISN, KHK and MC conceived and designed the study. HJJ managed the experimental plants, collected samples, prepared cDNA and performed qPCR analysis. NJ and IH prepared samples for HPLC. RKM wrote the manuscript. All authors read and approved the final manuscript.

\section{Competing interests}

The authors declare that there is no conflict of interest regarding the publication of this paper.

\section{Consent for publication}

Not applicable.

\section{Ethics approval and consent to participate}

Not applicable.

\section{Author details}

'Department of Horticulture, Sunchon National University, 255, Jungang-ro, Suncheon, Jeonnam 57922, Republic of Korea. ${ }^{2}$ Department of Fisheries Science, Chonnam National University, 50, Daehak-ro, Yeosu, Jeonnam 59626, Republic of Korea. ${ }^{3}$ Department of Agricultural Education, Sunchon National University, 255, Jungang-ro, Suncheon, Jeonnam 57922, Republic of Korea. ${ }^{4}$ Present address: Department of Horticulture, Sunchon National University, 255 Jungang-ro, Suncheon, Jeonnam 57922, Republic of Korea.

Received: 15 July 2016 Accepted: 16 December 2016

Published online: 11 January 2017

\section{References}

1. Singh P, Goyal GK. Dietary Lycopene: its properties and anticarcinogenic effects. Compr Rev Food Sci Food Saf. 2008;7(3):255-70.

2. Gould W. Tomato production, processing and technology. Baltimore: CTI Publications; 1992.

3. Chen L, Stacewicz-Sapuntzakis M, Duncan C, Sharifi R, Ghosh L, van Breemen $\mathrm{R}$, et al. Oxidative DNA damage in prostate cancer patients consuming tomato sauce-based entrees as a whole-food intervention. J Natl Cancer Inst. 2001;93(24):1872-9.

4. Sesso HD, Buring JE, Zhang SM, Norkus EP, Gaziano JM. Dietary and plasma lycopene and the risk of breast cancer. Cancer Epidemiol Biomarkers Prev. 2005;14(5):1074-81.

5. Francis FJ. Color quality evaluation of horticultural corps. HortSci. 1980; 15(1):58-9.

6. Tanaka Y, Sasaki N, Ohmiya A. Biosynthesis of plant pigments: anthocyanins, betalains and carotenoids. Plant J. 2008;54(4):733-49.
7. Lee JM, Joung JG, McQuinn R, Chung MY, Fei Z, Tieman D, et al. Combined transcriptome, genetic diversity and metabolite profiling in tomato fruit reveals that the ethylene response factor SIERF6 plays an important role in ripening and carotenoid accumulation. Plant J. 2012;70(2):191-204.

8. Bramley PM. Regulation of carotenoid formation during tomato fruit ripening and development. J Exp Bot. 2002;53(377):2107-13.

9. Britton G. Overview of carotenoid biosynthesis, in Carotenoids. In: Britton SL-J G, Pfander H, editors. Birkhauser Verlag, vol. 3. Basel, Switzerland. 1998. p. 13-147.

10. Hirschberg J. Molecular biology of carotenoid biosynthesis, in Carotenoids. In: Britton SL-J G, Pfander H, editors. Birkhauser Verlag, vol. 3. Basel, Switzerland. 1998. p. 149-94.

11. Lichtenthaler HK. The 1-Deoxy-D-xylulose-5-phosphate pathway of isoprenoid biosynthesis in plants. Annu Rev Plant Physiol Plant Mol Biol. 1999;50:47-65.

12. Cunningham FX, Gantt E. Genes and enzymes of carotenoid biosynthesis in plants. Annu Rev Plant Physiol Plant Mol Biol. 1998:49:557-83.

13. Hirschberg J. Carotenoid biosynthesis in flowering plants. Curr Opin Plant Biol. 2001:4(3):210-8.

14. Fraser PD, Kiano JW, Truesdale MR, Schuch W, Bramley PM. Phytoene synthase-2 enzyme activity in tomato does not contribute to carotenoid synthesis in ripening fruit. Plant Mol Biol. 1999;40(4):687-98.

15. Fantini E, Falcone G, Frusciante S, Giliberto L, Giuliano G. Dissection of tomato lycopene biosynthesis through virus-induced gene silencing. Plant Physiol. 2013;163(2):986-98.

16. Hwang I, Kim Y, Han J, Nou IS. Orange color is associated with CYC-B expression in tomato fleshy fruit. Mol Breed. 2016;36(4):1-10.

17. Ronen G, Carmel-Goren L, Zamir D, Hirschberg J. An alternative pathway to beta -carotene formation in plant chromoplasts discovered by map-based cloning of beta and old-gold color mutations in tomato. Proc Natl Acad Sci U S A. 2000;97(20):11102-7.

18. Sakuraba Y, Park SY, Paek NC. The Divergent roles of STAYGREEN (SGR) homologs in chlorophyll degradation. Mol Cells. 2015;38(5):390-5.

19. Barry CS, McQuinn RP, Chung M-Y, Besuden A, Giovannoni JJ. Amino acid substitutions in homologs of the STAY-GREEN protein are responsible for the green-flesh and chlorophyll retainer mutations of tomato and pepper. Plant Physiol. 2008;147(1):179-87.

20. Park SY, Yu JW, Park JS, Li J, Yoo SC, Lee NY, et al. The senescence-induced staygreen protein regulates chlorophyll degradation. Plant Cell. 2007;19(5):1649-64.

21. Efrati A, Eyal Y, Paran I. Molecular mapping of the chlorophyll retainer (cl) mutation in pepper (Capsicum spp.) and screening for candidate genes using tomato ESTs homologous to structural genes of the chlorophyll catabolism pathway. Genome. 2005;48(2):347-51.

22. Roca M, Minguez-Mosquera MI. Chlorophyll catabolism pathway in fruits of Capsicum annuum (L.): stay-green versus red fruits. J Agric Food Chem. 2006:54(11):4035-40.

23. Armstead I, Donnison I, Aubry S, Harper J, Hortensteiner S, James C, et al. From crop to model to crop: identifying the genetic basis of the staygreen mutation in the Lolium/Festuca forage and amenity grasses. New Phytol. 2006;172(4):592-7

24. Armstead I, Donnison I, Aubry S, Harper J, Hortensteiner S, James C, et al. Cross-species identification of Mendel's I locus. Science. 2007;315(5808):73.

25. Ren G, An K, Liao Y, Zhou X, Cao Y, Zhao H, et al. Identification of a nove chloroplast protein AtNYE1 regulating chlorophyll degradation during leaf senescence in Arabidopsis. Plant Physiol. 2007:144(3):1429-41.

26. Sato Y, Morita R, Nishimura M, Yamaguchi H, Kusaba M. Mendel's green cotyledon gene encodes a positive regulator of the chlorophyll-degrading pathway. Proc Natl Acad Sci U S A. 2007;104(35):14169-74.

27. Borovsky Y, Paran I. Chlorophyll breakdown during pepper fruit ripening in the chlorophyll retainer mutation is impaired at the homolog of the senescence-inducible stay-green gene. Theor Appl Genet. 2008;117(2):235-40.

28. Bovy A, Schijlen E, Hall RD. Metabolic engineering of flavonoids in tomato (Solanum lycopersicum): the potential for metabolomics. Metabolomics. 2007;3:399-412.

29. Veerappan Karpagam HJJ, Indeok H, Kang Hee K, Mi Young C, III Sup N. Sequence variation in SIMYB12 is associated with fruit peel color in pink tomato cultivars. Hortic Environ Biotechnol. 2016:57(3):274-9.

30. Barry CS, Pandey P. A survey of cultivated heirloom tomato varieties identifies four new mutant alleles at the green-flesh locus. Mol Breed. 2009; 24(3):269-76. 
31. Hortensteiner S. Stay-green regulates chlorophyll and chlorophyll-binding protein degradation during senescence. Trends Plant Sci. 2009;14(3):155-62.

32. Fujisawa M, Nakano T, Shima Y, Ito Y. A large-scale identification of direct targets of the tomato MADS box transcription factor RIPENING INHIBITOR reveals the regulation of fruit ripening. Plant Cell. 2013;25(2):371-86.

33. Silletti MF, Petrozza A, Stigliani AL, Giorio G, Cellini F, D’Ambrosio C, et al. An increase of lycopene content in tomato fruit is associated with a novel Cyc-B allele isolated through TILLING technology. Mol Breed. 2013;31(3):665-74.

34. Mohan V, Pandey A, Sreelakshmi Y, Sharma R. Neofunctionalization of chromoplast specific lycopene beta cyclase gene (CYC-B) in tomato clade. PLOS ONE. 2016;11(4):e0153333.

35. Pandurangaiah S, Ravishankar KV, Shivashankar KS, Sadashiva AT, Pillakenchappa K, Narayanan SK. Differential expression of carotenoid biosynthetic pathway genes in two contrasting tomato genotypes for lycopene content. J Biosci. 2016:41(2):257-64.

36. Kuntz M, Romer S, Suire C, Hugueney P, Weil JH, Schantz R, et al. Identification of a cDNA for the plastid-located geranylgeranyl pyrophosphate synthase from Capsicum annuum: correlative increase in enzyme activity and transcript level during fruit ripening. Plant J. 1992;2(1):25-34.

37. Bouvier F, d'Harlingue A, Hugueney P, Marin E, Marion-Poll A, Camara B. Xanthophyll biosynthesis. Cloning, expression, functional reconstitution, and regulation of beta-cyclohexenyl carotenoid epoxidase from pepper (Capsicum annuum). J Biol Chem. 1996;271(46):28861-7.

38. Bouvier F, d'Harlingue A, Suire C, Backhaus RA, Camara B. Dedicated roles of plastid transketolases during the early onset of isoprenoid biogenesis in pepper fruits1. Plant Physiol. 1998;117(4):1423-31.

39. Hugueney P, Bouvier F, Badillo A, Quennemet J, d'Harlingue A, Camara B. Developmental and stress regulation of gene expression for plastid and cytosolic isoprenoid pathways in pepper fruits. Plant Physiol. 1996;111(2):619-26.

40. Alba R, Payton P, Fei Z, McQuinn R, Debbie P, Martin GB, et al. Transcriptome and selected metabolite analyses reveal multiple points of ethylene control during tomato fruit development. Plant Cell. 2005;17(11): 2954-65.

41. Pretty J, Peacock J, Hine R, Sellens M, South N, Griffin M. Green exercise in the UK countryside: effects on health and psychological well-being, and implications for policy and planning. J Environ Plan Manag. 2007;50(2):211-31.

42. Tzoulas K, Korpela K, Venn S, Yli-Pelkonen V, Kaźmierczak A, Niemela J, et al. Promoting ecosystem and human health in urban areas using green infrastructure: a literature review. Landsc Urban Plan. 2007;81(3):167-78.

43. Sgherri C, Perez-Lopez, U, Pinzino, C. Antioxidant Properties of Food Products Containing Lycopene are Increased by the Presence of Chlorophyll. In: Lycopene: Food Sources, Potential Role in Human Health and Antioxidant Effects Edited by bailey JR. New York: Nova Science Publishers, inc; 2015. p. 39-90.

44. Fahey JW, Stephenson KK, Dinkova-Kostova AT, Egner PA, Kensler TW, Talalay P. Chlorophyll, chlorophyllin and related tetrapyrroles are significant inducers of mammalian phase 2 cytoprotective genes. Carcinogenesis. 2005; 26(7):1247-55

45. Balder HF, Vogel J, Jansen MC, Weijenberg MP, van den Brandt PA, Westenbrink S, et al. Heme and chlorophyll intake and risk of colorectal cancer in the Netherlands cohort study. Cancer Epidemiol Biomarkers Prev. 2006;15(4):717-25

46. Nyman ES, Hynninen PH. Research advances in the use of tetrapyrrolic photosensitizers for photodynamic therapy. J Photochem Photobiol B. 2004; 73(1-2):1-28.

47. Thomas H, Howarth CJ. Five ways to stay green. J Exp Bot. 2000;51 suppl 1:329-37.

48. Aziz ur R, Imran $H$, Nadeem A, Mumtaz $H$, Khan MA, Jehanzeb F, et al. Screening wheat germplasm for heat tolerance at terminal growth stage. Plant Omics. 2009;2(1):9-19.

\section{Submit your next manuscript to BioMed Central and we will help you at every step:}

- We accept pre-submission inquiries

- Our selector tool helps you to find the most relevant journal

- We provide round the clock customer support

- Convenient online submission

- Thorough peer review

- Inclusion in PubMed and all major indexing services

- Maximum visibility for your research

Submit your manuscript at www.biomedcentral.com/submit
Biomed Central 